\title{
Research activity does not affect nest predation rates of the Silver-throated Tit, a passerine bird building domed nests
}

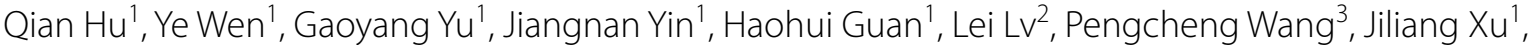 \\ Yong Wang ${ }^{4}$, Zhengwang Zhang ${ }^{5}$ and Jianqiang $\mathrm{Li}^{1^{*}}$ (D)
}

\begin{abstract}
Background: Research activities have often been thought to potentially influence avian nesting success by increasing nest predation rates. Although recent studies of species building open nests and cavity nests suggest that research disturbance does not generally induce nest predation, whether it is also the case in species building domednests remains unknown. In birds, domed-nest species exist in about half of the passerine families, and research disturbance to the domed nests may differ from that to the nests of other types for their different nest structures.

Methods: We investigated if research activities affected nest predation rate by analyzing the relationships of the daily nest survival rate with the research activities at the egg and nestling stages of a domed-nest species, the Silverthroated Tit (Aegithalos glaucogularis).

Results: Our results showed that nest daily survival rate was significantly affected by the laying date and nest age during the egg stage, and by the hatching date only during the nestling stage. By contrast, there were no significant effects of research activities, in terms of visiting nests and filming nests, on the nest survival of the Silver-throated Tit at both the egg and nestling stages.

Conclusions: Our results coincide with the findings in species building other types of nests that research activities do not always have negative effects on avian nesting success.
\end{abstract}

Keywords: Aegithalos glaucogularis, Nest filming, Nest predation, Nest survival, Nest visit, Research disturbance

\section{Background}

There have been long-existing concerns of threats of human activities to birds (Chalfoun et al. 2002; Bocz et al. 2017; Rosenberg et al. 2019). It has been recognized that various human activities may pose negative effects on birds. For instance, human activities may cause habitat fragmentations, which can elevate nest predation rates by increasing edge effects (Chalfoun et al. 2002; Batáry and Báldi 2004). Also, human activities such as touring and

*Correspondence: lijianqiang@bjfu.edu.cn

${ }^{1}$ School of Ecology and Nature Conservation, Beijing Forestry University, Beijing 100083, China

Full list of author information is available at the end of the article hiking can flush the adults from the nest, leaving eggs and nestlings unattended and thus vulnerable to predation (Steven et al. 2011; Stien and Ims 2016).

The researches on wild birds, as one type of the most direct human activities toward birds, have also received a lot of attention about whether they influence birds' nesting success, not only by the public but also the researchers themselves (e.g., Ibáñez-Álamo et al. 2012; Gibson et al. 2015; Stein et al. 2017). Researches on birds include a wide range of activities such as frequent visits to nests (e.g., Blackmer et al. 2004; Ibáñez-Álamo and Soler 2010) and handling the birds (e.g., Carey 2011; Orzechowski et al. 2019). Research activities have been thought to have

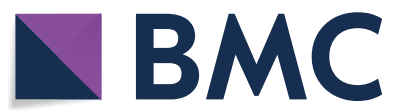

(c) The Author(s) 2020. This article is licensed under a Creative Commons Attribution 4.0 International License, which permits use, sharing, adaptation, distribution and reproduction in any medium or format, as long as you give appropriate credit to the original author(s) and the source, provide a link to the Creative Commons licence, and indicate if changes were made. The images or other third party material in this article are included in the article's Creative Commons licence, unless indicated otherwise in a credit line to the material. If material is not included in the article's Creative Commons licence and your intended use is not permitted by statutory regulation or exceeds the permitted use, you will need to obtain permission directly from the copyright holder. To view a copy of this licence, visit http://creativeco mmons.org/licenses/by/4.0/. The Creative Commons Public Domain Dedication waiver (http://creativecommons.org/publicdomain/ zero/1.0/) applies to the data made available in this article, unless otherwise stated in a credit line to the data. 
potentially negative effects on the nesting success of birds for reasons like attracting predators due to destroying vegetation and leaving human odor to the nests (Götmark 1992; Gutzwiller et al. 2002; Carey 2009). However, although some studies have shown that research disturbance can result in higher nest predation (Major 1990; Meixell and Flint 2017; Zhao et al. 2020), others have not found a significant effect (Monroe et al. 2014; Ledwoń et al. 2016; Orzechowski et al. 2019). Moreover, some studies have even reported a positive effect of research activities on nest survival in some avian taxon (Herranz et al. 2002; Richardson et al. 2009; Ibáñez-Álamo and Soler 2010), possibly because the presence of humans or conspicuous nest-monitoring devices may deter predators (MaCivor et al. 1990; Richardson et al. 2009).

Among various types of research disturbances, researchers' visits to nests are probably one of the most common disturbing activities in studies of bird breeding ecology, because researchers often need to visit nests frequently to collect data on breeding parameters (e.g. Walker et al. 2004; Li et al. 2019). In this regard, most studies have not detected any effect of nest visits on birds' nest survival (reviewed in Ibáñez-Álamo et al. 2012). Nevertheless, the effect of researchers' visits to nests can vary widely among species and even within the same habitat (Weidinger 2008; Ibáñez-Álamo et al. 2012). Therefore, system-specific researches have been encouraged (Ibáñez-Álamo and Soler 2010). Moreover, it is noticeable that most of the studies have focused on the effects of research activities on the nest survival of the species building open nests (e.g., Weidinger 2008; Ibáñez-Álamo and Soler 2010; Gibson et al. 2015), and a few on the species building cavity nests (e.g., Rodway et al. 1996; Blackmer et al. 2004; Carey 2011). To the best of our knowledge, studies on whether research activities influence nest survival of species building domed nests are surprisingly missing, despite that these species are present in 52\% of passerine families (Collias 1997). However, the disturbance of research activities on domed nests may differ from that on the other types of nests for at least three reasons. Firstly, different types of nests are subjected to different predation risk. For example, the domed nests (together with cavity nests) are thought to have reduced detectability of nest contents by predators compared with open nests (Mainwaring et al. 2015), although it has been reported recently that enclosed nests can alter the sound waves of nestling begging calls in ways that nest detection by a predator may be increased and thus result in a higher predation risk at nestling stage than the open nests (Mouton and Martin 2019). Secondly, unlike the open nests where the nest contents can be usually seen without touching the nest, the domed nests (and cavity nests) are often closely touched by the researchers during nest checks to record breeding parameters (e.g. laying date, clutch and brood sizes) and confirm nest status (e.g. alive or predated), which leaves more disturbance to nests. Thirdly, although the domed nests, which are usually made of plant fibers, also represent one type of the enclosed nests, research activities may produce severer effects on them than on cavity nests as they are much easier to be destroyed by predators than the cavity nests that are usually placed in tree and cliff holes. These differences hence make it necessary to further investigate whether research activities affect nest predation in bird species building domed nests.

To fill this gap, our study examines the relationship between nest visit activities by researchers and the daily nest survival rate (DSR) of a domed-nest species, the Silver-throated Tit (Aegithalos glaucogularis), for both the egg stage (i.e. egg-laying and incubation stage) and the nestling stage, respectively.

\section{Methods \\ Study populations}

The Silver-throated Tit population we studied was located in the Dongzhai National Nature Reserve $\left(31^{\circ} 57 \mathrm{~N}, 114^{\circ} 15 \mathrm{E}\right)$ in the south of Henan Province, China, and the data for this study were collected from 2011 to 2018. This species is resident at the study site and the breeding season usually starts in late January or early February and lasts until late May or early June ( $\mathrm{Li}$ et al. 2012). Silver-throated Tit builds domed-nests with an entrance hole on the side near the top. Nests are placed on various plants such as trees like Chinese Fir (Cunninghamia lanceolata) and Masson Pine (Pinus massoniana) and shrubs like tea and rosaceous plants, with nest height varying from 0.15 to $10 \mathrm{~m}$ above the ground ( $\mathrm{Li}$ et al. 2012; Guan et al. 2018). The apparent nesting success of Silver-throated Tit is $\sim 30 \%$, with the nest abandonment being the main reason for nest failures during the nestbuilding stage, and predation during the egg and nestling stages (Li et al. 2012; Guan et al. 2018). The nest predators of this species are mostly birds and snakes in our study area, and predation accounts for $~ 70 \%$ nest failure during our study periods (Li et al. 2012; Guan et al. 2018).

\section{Nest monitoring}

During the study, most of the nests were found at the nest-construction stage by following adults that were carrying nest materials ( $\mathrm{Li}$ et al. 2012). To monitor the nest fate and breeding stage, we checked most nests every 3 to 5 days at the nest-construction stage, every 2 or 3 days at the egg and nestling stages, and visited them every day when they were close to the laying of eggs or hatching of nestlings. For the accessible nests with a completed 


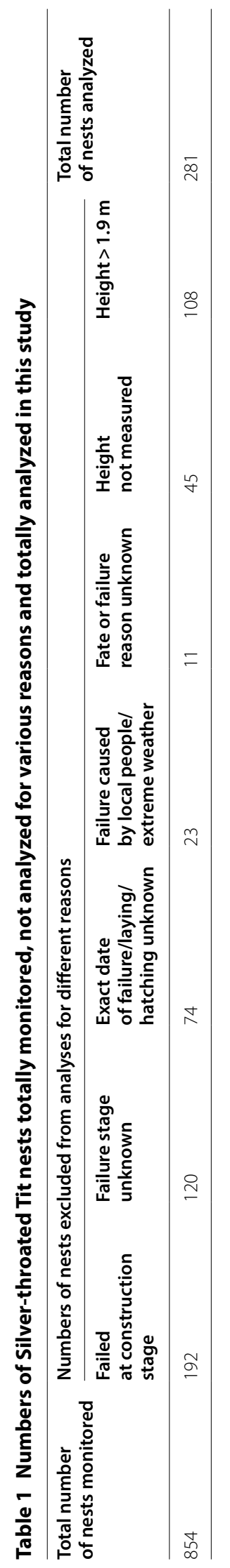


dome, we touched the nest content using fingers to determine the status of the nest during each visit. Alternatively, for the inaccessible nests (e.g. those on high trees), we usually observed the behaviors of the adults with binoculars to estimate the breeding stage and checked the intactness of the nest appearance to determine if they had been predated or not, because predation by birds and mammals often resulted in the destruction of a nest with the lining feathers outside. For the purpose of recording parental behaviors at nests such as incubation and nestling provisioning (e.g., Yu et al. 2016), some nests were filmed using video cameras that were covered with camouflaged fabric and set on tripods at a distance of $\geq 0.5 \mathrm{~m}$ from the nests. In addition, we measured eggs for each nest at the early incubation stage and banded nestlings when they were around 10 days old at the nestling stage, but because these activities usually took a short time $(<15 \mathrm{~min})$, we did not treat them differently from the other routine nest-checking activities in the analyses.

\section{Data analysis}

Our analyses focused on the effects of research activities on the DSR at the egg and nestling stages of the Silver-throated Tit. The nest-construction stage was not analyzed because even if a nest had been visited by a predator, we could hardly know it as there was no egg or the nestling loss, unless the nest was destroyed, which seldom happened (Li et al. 2012). Moreover, because the higher nests were usually inaccessible and thus the disturbance of nest visits was limited, we used only the nests with height being $\leq 1.9 \mathrm{~m}$ for the analyses. The height of $1.9 \mathrm{~m}$ was chosen based on the estimated height that our shortest field crew during the study could touch after raising her hand. The use of this arbitrary criterion means that some nests could be touched by our taller field crew but were excluded from analyses, despite that it reduced the sample sizes for our analyses. By using the low nests, we can assure that all the nests involved in the analyses were checked in a similar way, i.e. being touched when necessary. We had considered analyzing the nests that were higher than $1.9 \mathrm{~m}$ separately, but after excluding the nests where information such as exact failure date and failure reason were unknown, their sample size was too small to be properly analyzed in the current study (see Table 1).

We analyzed the effect of research activities on the DSR of the egg stage and the nestling stage, respectively, in that the two stages might differ in predation rates (Martin et al. 2000; McDonald et al. 2009). The analyses were conducted with the nest survival analysis procedure in program MARK 9.0 (White and Burnham 1999) via the R package 'RMark' (Laake 2013; Laake and Rexstad 2019) in $\mathrm{R}$ version 3.6.1 ( $\mathrm{R}$ Development Core Team 2019).
The procedure uses a generalized linear model with a logit-link function and binominals errors to estimate the relationship of the DSR with various covariates. The parameters in the encounter history of the nests included: FirstFound (the date when the nest was first found), LastPresent (the date when eggs/chicks were last found present), LastChecked (the date when the nest was last visited), Fate (the fate of the nest; $0=$ hatch/fledging and $1=$ depredated), Freq (the frequency of the nests with the same encounter history), AgeFound (the age of the nest when it was found, which was the number of days after its beginning of egg or nestling stage), and AgeDay1 (the number of days relative to the earliest date when the first egg of the population was laid and the first nestling hatched in each year for analyses of egg stage and nestling stage, respectively). In the analyses of nest survival at egg stage, the parameter "AgeFound" was estimated in the following ways: (1) for the nests that were found at the nest construction stage, it was set as 1-day-old; (2) if a nest was already at the egg stage when it was found, we estimated its age through a backdating method based on the fact that Silver-throated Tits lay one egg per day and have incubation periods $\sim 14$ days; (3) if a nest that was found at the incubation stage but failed before nestlings hatched, it was not included in the analyses because we were unable to estimate the nest age with the backdating method as we did not know the hatching date of the eggs. Similarly, in the analyses of the nest survival at the nestling stage, we set the parameter AgeFound as 1-dayold for the nests that were found before nestling stage and estimated the parameter of the nests that were found already at the nestling stage based on our prior knowledge of the body size of the nestlings at different ages ( $\mathrm{J}$. $\mathrm{Li}$, personal obsrevation).

The variables considered to explain the DSR in the model included the researchers' nest visit, nest filming, nest age, nest height, year and date. Researchers' nest visit was used to estimate the disturbing effect of the general research activities (i.e. checking nests, measuring eggs and banding chicks) where its value was set as "1" and "0" respectively for a nest being visited or not visited on a given day (Dinsmore and Dinsmore 2007). Nest filming was a variable to specifically estimate the effect of filming nests using cameras, because the use of cameras may affect nest predation rates according to a meta-analysis across species (Richardson et al. 2009); nest filming was set as " 1 " and "0" respecitively for a nest being filmed or not filmed on a given day. Nest age was included, because with the increase of nest age, both the behaviors of adult birds (Martin et al. 2000; McDonald et al. 2009) and the number of days that nests were exposed to predators (Klett and Johnson 1982) would change, which were likely to affect nest predation rates. Year and date were 
included because they have been found to affect the nest survival of this species (Guan et al. 2018). The date was the "laying date" in the analysis of egg-stage, which was calculated as the number of days from the date when the first egg of the nest was laid to the date when the population's first egg was laid in each year, and was "hatching date" in the analysis of nestling-stage, which was calculated as the number of days from the date when nestlings of the nest hatched to the date when the population's first nestling hatched in each year.

Possible combinations of global model terms were compared with the "dredge" function in the package 'MuMIn' (Bartoń 2019). The best models were ranked based on AICc (Akaike information criterion corrected for small sample size). Because there were disagreements in the cut-off criterion for choosing the best models (Burnham et al. 2011), we followed Moynahan et al. (2007) and Touihri et al. (2017) that considered models with $\triangle \mathrm{AICc}<4$ as having comparable support. The bestsupported models were then averaged using the "model. avg" function through package 'MuMIn' to account for model selection uncertainty. When $95 \%$ confidence intervals (CI) of parameter estimate of an explanatory variable overlapped with zero, we considered the variable to have little evidence to significantly affect the DSR (Zar 2014).

\section{Results}

From 2011 to 2018, we monitored a total of 854 Silverthroated Tit nests, but some nests were removed from our analyses for various reasons (Table 1). In the analyses of the egg stage using 266 Silver-throated Tit nests, the model selection results produced more than one bestsupported model, with researchers' nest visit and nest filming being included in the fourth-best and second-best model, respectively (Table 2 ). The averaged model contained all six variables (Table 3). The DSR was not significantly affected by the researchers' nest visit, nest filming, or nest height (Table 3). However, the DSR significantly decreased with the increase of the nest age and laying date (Table 3; Fig. 1a, b), and there were some yearly variations in the DSR during the study (Table 3).

In the analyses of the nestling stage using 202 nests, the model selection results again produced more than one best-supported model (Table 2). Researchers' nest visit was included in the fifth-best model, while nest filming was included in the $10^{\text {th }}$-best model (Table 2). The averaged model contained all six variables (Table 3). Neither researchers' nest visit nor nest filming activity significantly affected the DSR (Table 3). The DSR also did not significantly change with nest height (Table 3 ). Moreover, similar to the relationship between DSR and nest age at the egg stage, the DSR also tended to decrease with nest age (Fig. 1c), but the trend was not significant (Table 3). Besides, the DSR significantly decreased with the increase of the hatching date (Table 3; Fig. 1d), and there were some variations among years (Table 3 ).

\section{Discussion}

We have shown that the researchers' nest visits did not affect the DSR of the Silver-throated Tits in both the egg and nestling stages. Besides, although it has been found that the use of cameras may affect nest predation rates in other birds (Richardson et al. 2009), we found no significant effect in our study. Hence, our findings in the Silverthroated Tit coincide with most of the studies conducted in the species building open nests, which reported limited negative effects of research activities on nest predation rates (e.g., Weidinger 2008; Ibáñez-Álamo and Soler 2010; Ibáñez-Álamo et al. 2012).

The absence of significant relationships of research activities with the DSR of Silver-throated Tits may be explained by the following reasons. Firstly, it has been suggested that the nest predation of songbirds is not increased by repeated observer visits in areas where the background human disturbance is high (Weidinger 2008). Our study site locates in a rural area with local villagers frequently conducting outdoor activities (e.g., planting and collecting crops). Thus, the predators in this area may be unable to associate human activities with bird nests. Secondly, nest predators may either be attracted or deterred by human activities near nests (Gutzwiller et al. 2002; Lloyd and Plagányi 2002; Weidinger 2008). When some predators are attracted while others deterred, the combined effect may be ambiguous and not significant (Jacobson et al. 2011). Thirdly, the results may be because we have been cautious when checking nests, including, for example, avoiding to check a nest when predatory birds (e.g. jays and magpies) are present, and covering the cameras with camouflaged fabrics when filming nests, all of which may help to reduce potential negative effects of research activities. Moreover, we usually train the inexperienced crew members with certain nest-checking skills at the beginning of our each year's field work during the breeding season, so that the potential impact of researcher's experience on nest survival should have been somewhat reduced.

Despite the absence of significantly negative effects of research activities on nest survival in this study, however, we want to emphasize that attentions are still needed to reduce disturbance in studies of avian breeding ecology, because it may affect the accuracy of nest survival estimation and may cause some effects on birds that we may be unaware (e.g. elevated hormonal stress response; Ellenberg et al. 2007). In this respect, there has been some specific advice to follow. For example, 
Table 2 Model selection results of the best-supported model set $(\Delta \mathrm{AICc}<4)$ for daily nest survival rate at the egg and nestling stages of Silver-throated Tits

\begin{tabular}{|c|c|c|c|c|c|}
\hline Stages & Models & $k$ & LogLik & $\Delta \mathrm{AICc}$ & $w_{i}$ \\
\hline \multirow[t]{10}{*}{ Egg } & Date + NestAge + Year & 10 & -335.254 & $0.000^{\mathrm{a}}$ & 0.208 \\
\hline & Date + Filming + NestAge + Year & 11 & -335.043 & 1.588 & 0.094 \\
\hline & Date + NestAge + NestHeight + Year & 11 & -335.100 & 1.703 & 0.089 \\
\hline & Date + NestAge + Visit + Year & 11 & -335.147 & 1.798 & 0.085 \\
\hline & Date + Filming + NestAge + NestHeight + Year & 12 & -334.895 & 3.303 & 0.040 \\
\hline & Date + NestAge + NestHeight + Year & 12 & -334.994 & 3.502 & 0.036 \\
\hline & Date + Filming + NestAge + Visit + Year & 12 & -335.004 & 3.521 & 0.036 \\
\hline & Date + Year & 9 & -338.158 & 3.801 & 0.031 \\
\hline & Date + NestAge & 3 & -344.210 & 3.869 & 0.030 \\
\hline & NestAge + Year & 9 & -338.254 & 3.992 & 0.028 \\
\hline \multirow[t]{28}{*}{ Nestling } & Date + NestAge + Year & 10 & -316.314 & $0.000^{b}$ & 0.085 \\
\hline & Date + Year & 9 & -317.421 & 0.196 & 0.077 \\
\hline & Date + NestAge + NestHeight + Year & 11 & -315.504 & 0.401 & 0.069 \\
\hline & Date + NestHeight + Year & 10 & -316.606 & 0.583 & 0.063 \\
\hline & Date + NestAge + Visit + Year & 11 & -315.922 & 1.236 & 0.046 \\
\hline & Date + Visit & 3 & -324.022 & 1.327 & 0.044 \\
\hline & Date + NestAge + Visit & 4 & -323.084 & 1.458 & 0.041 \\
\hline & Date + NestAge + NestHeight + Visit + Year & 12 & -315.075 & 1.564 & 0.039 \\
\hline & Date & 2 & -325.185 & 1.647 & 0.037 \\
\hline & Date + Filming + NestAge + Year & 11 & -316.311 & 2.013 & 0.031 \\
\hline & Date + Visit + Year & 10 & -317.321 & 2.014 & 0.031 \\
\hline & Date + NestHeight + Visit & 4 & -323.447 & 2.184 & 0.028 \\
\hline & Date + Filming + Year & 10 & -317.413 & 2.198 & 0.028 \\
\hline & Date + NestAge + NestHeight + Visit & 5 & -322.491 & 2.281 & 0.027 \\
\hline & Date + NestHeight + Visit + Year & 11 & -316.486 & 2.364 & 0.026 \\
\hline & Date + Filming + NestAge + NestHeight + Year & 12 & -315.495 & 2.404 & 0.025 \\
\hline & Date + Filming + NestHeight + Year & 11 & -316.602 & 2.597 & 0.023 \\
\hline & Date + NestAge & 3 & -324.754 & 2.790 & 0.021 \\
\hline & Date + NestHeight & 3 & -324.760 & 2.802 & 0.021 \\
\hline & Date + Filming + NestAge + Visit + Year & 12 & -315.752 & 2.918 & 0.020 \\
\hline & Date + Filming + Visit & 4 & -323.862 & 3.013 & 0.019 \\
\hline & Date + Filming + NestAge + Visit & 5 & -322.894 & 3.087 & 0.018 \\
\hline & Date + Filming + NestAge + NestHeight + Visit + Year & 13 & -314.924 & 3.285 & 0.016 \\
\hline & Date + Filming & 3 & -325.009 & 3.301 & 0.016 \\
\hline & Date + Filming + Visit + Year & 11 & -317.186 & 3.764 & 0.013 \\
\hline & Date + Filming + NestHeight + Visit & 5 & -323.292 & 3.882 & 0.012 \\
\hline & Date + Filming + NestAge + NestHeight + Visit & 6 & -322.309 & 3.927 & 0.012 \\
\hline & Date + NestAge + NestHeight & 4 & -324.335 & 3.960 & 0.012 \\
\hline
\end{tabular}

Candidate variables included Visit (researchers' nest visit), Filming (nest filming), Date (for the egg-stage analysis, date is the number of days from the date when the first egg of a nest was laid to the date when the first egg of the population was laid in each year, i.e. laying date; for the nestling-stage analysis, date is the number of days from the date when nestlings of a nest hatched to the date when the first nestling of the population hatched in each year, i.e. hatching date), Year, NestAge (number of days after the first egg of the nest was laid or number of days after the nestlings of the nest hatched for the analyses of the egg-stage and nestling stages, respectively), NestHeight (nest height). $k$ is the number of model parameters. LogLik is the log-likelihood. Models are ranked based on the difference in corrected Akaike's Information Criterion ( $\triangle \mathrm{AICC})$ and model weight $\left(w_{i}\right)$

a Minimum AICc value $=690.557$

b Minimum AICc value $=652.728$ 
Table 3 Model-averaged parameter estimates and $95 \%$ confidence intervals (Cls) from the best model set for nest survival rate of Silver-throated Tits at egg and nestling stages

\begin{tabular}{|c|c|c|c|c|}
\hline \multirow[t]{2}{*}{ Parameters } & \multicolumn{2}{|l|}{ Egg stage } & \multicolumn{2}{|c|}{ Nestling stage } \\
\hline & Estimate & $95 \% \mathrm{Cl}$ & Estimate & $95 \% \mathrm{Cl}$ \\
\hline Intercept & 6.429 & $(4.695,8.163)$ & 3.944 & $(2.810,5.078)$ \\
\hline Date (laying/hatching) & $-0.031^{*}$ & $(-0.056,-0.007)$ & $-0.039^{*}$ & $(-0.067,-0.011)$ \\
\hline Nest age & $-0.047^{*}$ & $(-0.086,-0.008)$ & -0.038 & $(-0.090,0.013)$ \\
\hline Nest height & -0.159 & $(-0.724,0.406)$ & 0.337 & $(-0.219,0.894)$ \\
\hline Filming activity & 0.151 & $(-1.378,2.501)$ & -0.175 & $(-1.501,1.150)$ \\
\hline Researchers' nest visit activity & 0.045 & $(-0.566,0.868)$ & 0.525 & $(-0.466,1.517)$ \\
\hline Year 2012a & -1.345 & $(-3.152,0.463)$ & $-1.556^{*}$ & $(-2.586,-0.527)$ \\
\hline Year $2013^{a}$ & $-1.470^{*}$ & $(-2.985,-0.044)$ & -0.501 & $(-1.411,0.408)$ \\
\hline Year 2014 & $-2.071^{*}$ & $(-3.580,-0.562)$ & -0.925 & $(-1.864,0.014)$ \\
\hline Year $2015^{a}$ & -1.402 & $(-2.944,0.140)$ & -0.203 & $(-1.215,0.808)$ \\
\hline Year 2016 & -1.076 & $(-2.689,0.536)$ & -0.742 & $(-1.623,0.138)$ \\
\hline Year $2017^{a}$ & $-1.537^{*}$ & $(-3.036,-0.037)$ & -0.126 & $(-1.060,0.808)$ \\
\hline Year 2018 & $-2.102^{*}$ & $(-3.580,-0.625)$ & -1.117 & $(-2.037,0.197)$ \\
\hline
\end{tabular}

* indicates significant effect as assessed by no overlap of the $95 \% \mathrm{Cl}$ with zero

a Year 2011 is the reference category

one should assess the relative benefit of the information gained through the research against the possibility of affecting nest productivity or adult survival, as suggested by Ropert-Coudert et al. (2007). Moreover, when monitoring nests is inevitable, researchers need to balance activities between obtaining accurate data and reducing research disturbance, like to recover the trails before leaving the nests, check the nests from a distance as greater as possible, and do not approach a nest when any potential nest predator is present (Martin and Geupel 1993; Sutherland et al. 2004).

Our results also showed that the DSR significantly decreased with nest age at Silver-throated Tits' egg stage, and a similar trend (though non-significant) existed at its nestling stage (Table 3; Fig. 1a, c). In birds, the DSR can increase (Segura and Reboreda 2012), decrease (Jehle et al. 2004; Zhao et al. 2020), or have no significant relationship (Emery et al. 2005; Walker et al. 2005) with nest age. It has been suggested the increase of nest visit activities of incubating adults during the late incubation stage may provide cues for predators (Grant et al. 2005), although we do not know whether this is the situation in Silver-throated Tits. On the other hand, studies suggested that with the increase of the nest visit frequency of adult birds as well as the frequency and volume of the sounds produced by the growing nestlings, predators may be more likely to be attracted to nests, leading to reduced DSR when nest age increases (Leech and Leonard 1997; Briskie et al. 1999). Moreover, with the increase of nest age, the number of days that nests were exposed to predation increased, which could also facilitate predators to find the nest (Klett and Johnson 1982).

We have also shown that the DSR decreased with the increase of laying date at the egg stage and with the increase of hatching date at the nestling stage, and that there are some yearly variations in the DSR. These results agree with those of Guan et al.'s (2018) study on this Silver-throated Tit population. However, unlike Guan et al's (2018) finding of a negative relationship between nest height and DSR, this study did not find nest height to affect the DSR of Silver-throated Tits. This difference may be due to the involvement of different datasets between the two studies. Because the purpose of Guan et al's (2018) study was to investigate whether the seasonal change of nest height was adaptive, it included nests of all heights in the analysis. The present study, however, only included nests with a height lower than $1.9 \mathrm{~m}$.

\section{Conclusions}

Our study represents the first to test the effect of research disturbance on the DSR of the birds that build domed nests. The results did not find any significant effect of research activities on the nest survival at both the egg and nestling stages of Silver-throated Tits. Although we were unable to analyze whether the DSR was affected by researchers' visits to nests higher than $1.9 \mathrm{~m}$, we believe that the effect should have been limited, as we usually only stood at certain distances from the high nests and observed them by binoculars. Therefore, our results agree with those conducted in species building other types of nests which report that research 

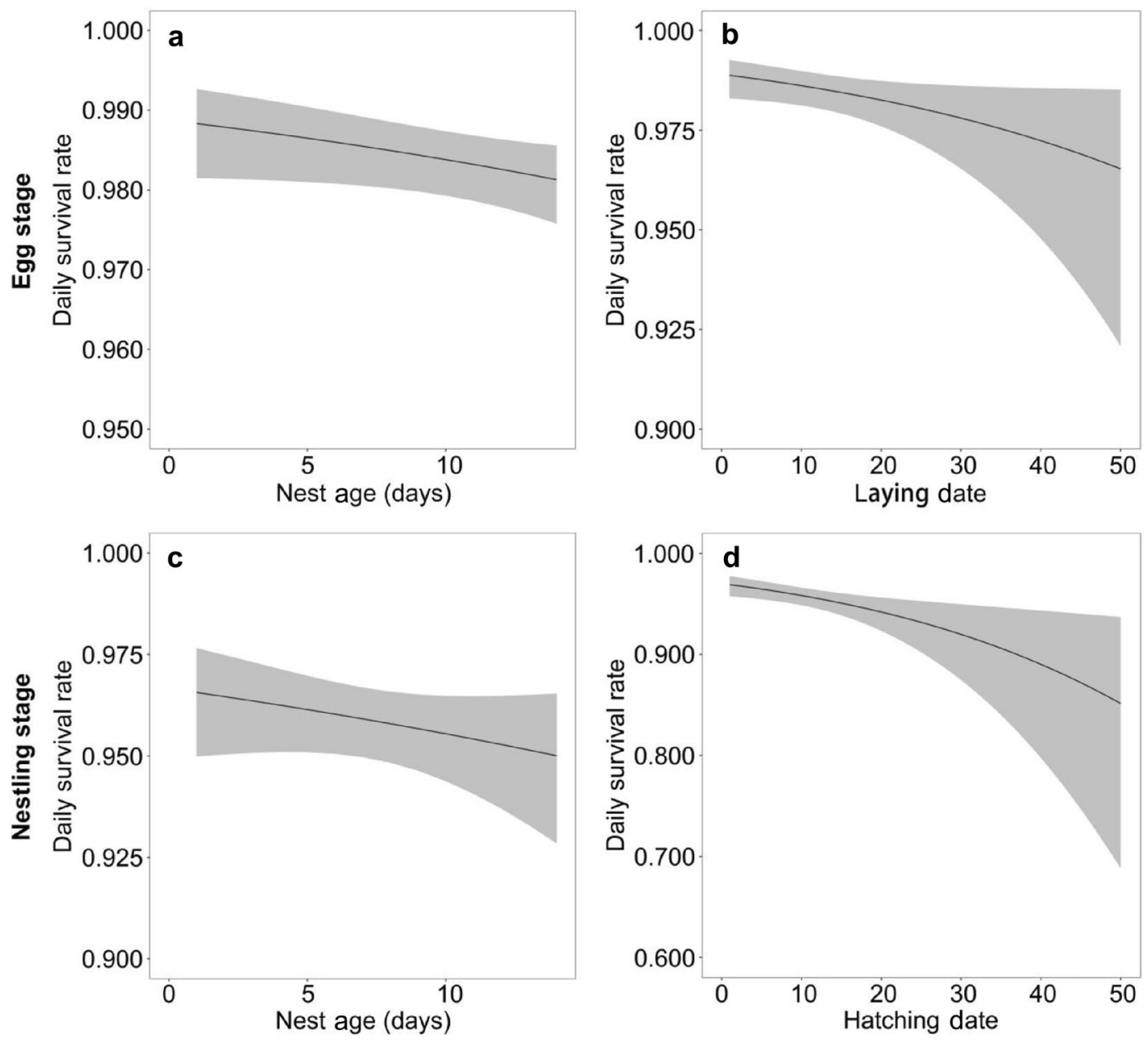

Fig. 1 Predicted daily survival rates (with $95 \%$ Cl) of Silver-throated Tit nests in relation to nest age (a) and laying date (b) at egg stage, and in relation to nest age $(\mathbf{c})$ and hatching date $(\mathbf{d})$ at nestling stage

disturbance does not generally lead to reduced avian nest survival (Weidinger 2008; Ibáñez-Álamo and Soler 2010; Ibáñez-Álamo et al. 2012). However, given the inadequacy of studies of research disturbance in species building domed nests, we suggest more studies to be conducted so as to confirm our findings and to get a more comprehensive understanding of research disturbance to domed-nest birds.

\section{Acknowledgements}

We thank the Dongzhai National Natural Reserve for the permission and assistance to conduct the fieldwork. We are also grateful to all the students and field assistants who helped with the data collection, Jeff Laake for helping with the data analyses and Andrea Parisi for editing the English of the manuscript.

\section{Authors' contributions}

$J \mathrm{~L}$ conceived the study; QH analyzed the data; all authors contributed to data collection and manuscript preparation. All authors read and approved the final manuscript.

\section{Funding}

This study was funded by the National Natural Science Foundation of China (Grant Nos. 31970421, 31472011, 31101644).

\section{Availability of data and materials}

The datasets used during the current study are available from the corresponding author on reasonable request.

\section{Ethics approval and consent to participate}

Our study was carried out in agreement with the Law of the People's Republic of China on the Protection of Wild life and was approved by the Administrative Bureau of Dongzhai National Nature Reserve.

\section{Consent for publication}

Not applicable.

\section{Competing interests}

The authors declare that they have no competing interests.

\section{Author details}

${ }^{1}$ School of Ecology and Nature Conservation, Beijing Forestry University, Beijing 100083, China. ${ }^{2}$ School of Life Sciences, Sun Yat-sen University, Guangzhou 510275, China. ${ }^{3}$ Key Laboratory of Animal Ecology and Conservation 
Biology, Institute of Zoology, Chinese Academy of Sciences, Beijing 100101, China. ${ }^{4}$ Department of Biological and Environmental Science, College of Agricultural, Life and Natural Sciences, Alabama A\&M University, Normal, AL 35762, USA. ${ }^{5}$ Ministry of Education Key Laboratory for Biodiversity Sciences and Ecological Engineering, College of Life Sciences, Beijing Normal University, Beijing 100875, China.

Received: 13 July 2020 Accepted: 30 July 2020

Published online: 03 August 2020

\section{References}

Bartoń K. Package MuMIn. R package version 1.43.6. 2019. http://cran.r-proje ct.org/web/packages/MuMln/index.html. Accessed 27 Oct. 2019.

Batáry P, Báldi A. Evidence of an edge effect on avian nest success. Conserv Biol. 2004;18:389-400.

Blackmer AL, Ackerman JT, Nevitt GA. Effects of investigator disturbance on hatching success and nest-site fidelity in a long-lived seabird, Leach's storm-petrel. Biol Conserv. 2004;116:141-8.

Bocz R, Szép D, Witz D, Ronczyk L, Kurucz K, Purger JJ. Human disturbances and predation on artificial ground nests across an urban gradient. Anim Biodivers Conserv. 2017;40:153-7.

Briskie JV, Martin PR, Martin TE. Nest predation and the evolution of nestling begging calls. Proc R Soc Lond B-Biol Sci. 1999;266:2153-9.

Burnham KP, Anderson DR, Huyvaert KP. AIC model selection and multimodel inference in behavioral ecology: some background, observations, and comparisons. Behav Ecol Sociobiol. 2011;65:23-35.

Carey MJ. The effects of investigator disturbance on procellariiform seabirds: a review. N Z J Zool. 2009;36:367-77.

Carey MJ. Investigator disturbance reduces reproductive success in Shorttailed Shearwaters Puffinus tenuirostris. Ibis. 2011;153:363-72.

Chalfoun AD, Ratnaswamy MJ, Thompson FR. Songbird nest predators in forest-pasture edge and forest interior in a fragmented landscape. Ecol Appl. 2002;12:858-67.

Collias NE. On the origin and evolution of nest building by passerine birds. Condor. 1997;99:253-70.

Dinsmore SJ, Dinsmore JJ. Modeling avian nest survival in program MARK. Stud Avian Biol. 2007;34:73-83.

Ellenberg U, Setiawan AN, Cree A, Houston DM, Seddon PJ. Elevated hormonal stress response and reduced reproductive output in Yellow-eyed penguins exposed to unregulated tourism. Gen Comp Endocrinol. 2007;152:54-63.

Emery RB, Howerter DW, Armstrong LM, Anderson MG, Devries JH, Joynt BL. Seasonal variation in waterfowl nesting success and its relation to cover management in the Canadian prairies. J Wildl Manage. 2005;69:1 181-93.

Gibson D, Blomberg EJ, Atamian MT, Sedinger JS. Observer effects strongly influence estimates of daily nest survival probability but do not substantially increase rates of nest failure in Greater Sage-Grouse. Auk. 2015;132:397-407.

Götmark F. The effects of investigator disturbance on nesting birds. In: Power DM, editor. Current Ornithology. Boston: Springer; 1992. p. 63-104.

Grant TA, Shaffer TL, Madden EM, Pietz PJ. Time-specific variation in passerine nest survival: new insights into old questions. Auk. 2005;122:661-72.

Guan H, Wen Y, Wang P, Lv L, Xu J, Li J. Seasonal increase of nest height of the Silver-throated Tit (Aegithalos glaucogularis): can it reduce predation risk? Avian Res. 2018;9:42.

Gutzwiller KJ, Riffell SK, Anderson SH. Repeated human intrusion and the potential for nest predation by gray jays. J Wildl Manage. 2002;66:372.

Herranz J, Yanes M, Suárez F. Does photo-monitoring affect nest predation? J Field Ornithol. 2002;73:97-101.

Ibáñez-Álamo JD, Sanllorente O, Soler M. The impact of researcher disturbance on nest predation rates: a meta-analysis. Ibis. 2012;154:5-14.

Ibáñez-Álamo JD, Soler M. Investigator activities reduce nest predation in blackbirds Turdus merula. J Avian Biol. 2010;41:208-12.

Jacobson MD, Tsakiris ET, Long AM, Jensen WE. No evidence for observer effects on Lark Sparrow nest survival. J Field Ornithol. 2011;82:184-92.

Jehle G, Adams AA, Savidge JA, Skagen SK. Nest survival estimation: a review of alternatives to the Mayfield estimator. Condor. 2004;106:472-84.

Klett AT, Johnson DH. Variability in nest survival rates and implications to nesting studies. Auk. 1982;99:77-87.
Laake JL. RMark: An R interface for analysis of Capture-Recapture data with MARK. Seattle: National Marine Mammal Laboratory, Alaska Fisheries Science Center; 2013.

Laake JL, Rexstad E. R code for MARK analysis. R package version 2.2.6. 2019. https://cran.r-project.org/web/packages/RMark/index.html. Accessed 14 Aug. 2019.

Ledwoń M, Betleja J, Neubauer G. Different trapping schemes and variable disturbance intensity do not affect hatching success of Whiskered Terns Chlidonias hybrida. Bird Study. 2016;63:136-40.

Leech SM, Leonard ML. Begging and the risk of predation in nestling birds. Behav Ecol. 1997;8:644-6.

Li J, Lv L, Wang Y, Xi B, Zhang Z. Breeding biology of two sympatric Aegithalos tits with helpers at the nest. J Ornithol. 2012;153:273-83.

Li J, Wang Y, Lv L, Wang P, Hatchwell BJ, Zhang Z. Context-dependent strategies of food allocation among offspring in a facultative cooperative breeder. Behav Ecol. 2019;30:975-85.

Lloyd P, Plagányi ÉE. Correcting observer effect bias in estimates of nesting success of a coastal bird, the White-fronted Plover Charadrius marginatus. Bird Study. 2002;49:124-30.

MaCivor LH, Melvin SM, Griffin CR. Effects of research activity on piping plover nest predation. J Wildl Manage. 1990;54:443.

Mainwaring MC, Reynolds SJ, Weidinger K. The influence of predation on the location and design of nests. In: Deeming DC, Reynolds SJ, editors. Nests, eggs, and incubation: new ideas about avian reproduction. New York: Oxford University Press; 2015. p. 50-64.

Major RE. The effect of human observers on the intensity of nest predation. Ibis. 1990;132:608-12

Martin TE, Geupel GR. Nest-monitoring plots methods for locating nests and monitoring success. J Field Ornithol. 1993;64:507-19.

Martin TE, Scott J, Menge C. Nest predation increases with parental activity: separating nest site and parental activity effects. Proc R Soc B-Biol Sci. 2000;267:2287-93.

McDonald PG, Wilson DR, Evans CS. Nestling begging increases predation risk, regardless of spectral characteristics or avian mobbing. Behav Ecol. 2009:20:821-9.

Meixell BW, Flint PL. Effects of industrial and investigator disturbance on arcticnesting geese. J Wildl Manage. 2017:81:1372-85.

Monroe AP, Martin JA, Riffell SK, Burger LW. Effects of measuring nestling condition on nest success in the dickcissel (Spiza americana). Wildl Soc Bull. 2014;38:401-6.

Mouton JC, Martin TE. Nest structure affects auditory and visual detectability, but not predation risk, in a tropical songbird community. Funct Ecol. 2019;33:1973-81.

Moynahan BJ, Lindberg MS, Rotella JJ, Thomas JW. Factors affecting nest survival of greater sage-grouse in northcentral Montana. J Wildl Manage. 2007;71:1773-83.

Orzechowski SCM, Shipley JR, Pegan TM, Winkler DW. Negligible effects of blood sampling on reproductive performance and return rates of Tree Swallows. J Field Ornithol. 2019;90:21-38.

R Development Core Team. R: A language and environment for statistical computing version 3.1.6. Vienna, Austria: R Foundation for Statistical Computing; 2019. https://www.r-project.org/.

Richardson TW, Gardali T, Jenkins SH. Review and meta-analysis of camera effects on avian nest success. J Wildl Manage. 2009;73:287-93.

Rodway MS, Montevecchi WA, Chardine JW. Effects of investigator disturbance on breeding success of Atlantic puffins Fratercula arctica. Biol Conserv. 1996;76:311-9.

Ropert-Coudert Y, Knott N, Chiaradia A, Kato A. How do different data logger sizes and attachment positions affect the diving behaviour of little penguins? Deep Res Part II-Top Stud Oceanogr. 2007;54:415-23.

Rosenberg KV, Dokter AM, Blancher PJ, Sauer JR, Smith AC, Smith PA, et al. Decline of the North American avifauna. Science. 2019;366:120-4.

Segura LN, Reboreda JC. Nest survival rates of Red-crested Cardinals increase with nest age in south-temperate forests of Argentina. J Field Ornithol. 2012;83:343-50.

Stein A, Young MJ, Seddon PJ, Darby JT, van Heezik Y. Investigator disturbance does not reduce annual breeding success or lifetime reproductive success in a vulnerable long-lived species, the yellow-eyed penguin. Biol Conserv. 2017;207:80-9.

Steven R, Pickering C, Guy Castley J. A review of the impacts of nature based recreation on birds. J Environ Manage. 2011;92:2287-94. 
Stien J, Ims RA. Absence from the nest due to human disturbance induces higher nest predation risk than natural recesses in Common Eiders Somateria mollissima. Ibis. 2016;158:249-60.

Sutherland WJ, Newton I, Green R. Bird ecology and conservation: a handbook of techniques. Oxford and New York: Oxford University Press; 2004. p. $62-4$

Touihri M, Charfi F. Villard MA. Effects of landscape composition and native oak forest configuration on cavity-nesting birds of North Africa. For Ecol Manage. 2017:385:198-205.

Walker J, Lindberg MS, Maccluskie MC, Petrula MJ, Sedinger JS. Nest survival of scaup and other ducks in the boreal forest of Alaska. J Wildl Manage. 2005;69:582-91.

Weidinger K. Nest monitoring does not increase nest predation in opennesting songbirds: inference from continuous nest-survival data. Auk. 2008;125:859-68.
White GC, Burnham KP. Program MARK: survival estimation from populations of marked animals. Bird Study. 1999;46:S120-39.

Yu J, Wang PC, Lü L, Zhang ZW, Wang Y, Xu JL, et al. Diurnal brooding behavior of long-tailed tits (Aegithalos caudatus glaucogularis). Zool Res. 2016;37:84-9.

Zar JH. Biostatistical analysis. 5th ed. Essex: Pearson Education Limited; 2014.

Zhao JM, Yang C, Lou YQ, Shi M, Fang Y, Sun YH. Nesting season, nest age, and disturbance, but not habitat characteristics, affect nest survival of Chinese grouse. Curr Zool. 2020;66:29-37.
Ready to submit your research? Choose BMC and benefit from:

- fast, convenient online submission

- thorough peer review by experienced researchers in your field

- rapid publication on acceptance

- support for research data, including large and complex data types

- gold Open Access which fosters wider collaboration and increased citations

- maximum visibility for your research: over 100M website views per year

At BMC, research is always in progress.

Learn more biomedcentral.com/submissions 